\title{
Orbital haemorrhage and prolonged blindness: a treatable posterior optic neuropathy
}

\author{
BARRETT KATZ, ${ }^{2}$ JONATHAN HERSCHLER, ${ }^{1}$ AND DEAN C. BRICK ${ }^{1}$ \\ From the Departments of ${ }^{1}$ Ophthalmology and ${ }^{2}$ Neurology, University of Arizona Health Sciences Center, \\ Tucson, Arizona, USA
}

SUMmaRY Two patients developed traumatic orbital haemorrhage resulting in prolonged blindness. Orbital decompression successfully reversed the visual loss, though both eyes had no light perception for at least $3 \frac{1}{2}$ hours. The clinical findings suggest damage to the posterior optic nerve as cause of the visual loss. The optic nerve tolerance time to ischaemic injury may be longer than previously thought.

Visual loss secondary to orbital haemorrhage has been appreciated by clinicians in the fields of ophthalmology and otolaryngology as well as those in plastic, dental, and neurological surgery..$^{17}$ Most frequently it is seen following trauma. ${ }^{8}$ Visual loss secondary to increased orbital contents from an infectious process has been seen in cellulitis and sinusitis, ${ }^{19-22}$ with orbital foreign body and abscess formation, ${ }^{23}$ and as a sequela of delayed treatment of a dental abscess. ${ }^{24}$ 'Spontaneous' orbital haemorrhage has been recorded with local disease ${ }^{1825-27}$ and associated with concurrent systemic disease. ${ }^{1828-31}$

Suggested explanations for this visual loss include central retinal artery or vein occlusion, acute glaucoma, anterior ischaemic optic neuropathy, reflex vasospasm of the retinal vasculature, toxic or metabolic ischaemia, optic nerve sheath haemorrhage, optic nerve avulsion, and excessive tugging by orbital fat on nutrient vessels to the optic nerve.

We recently treated 2 patients with total loss of vision from traumatic orbital haemorrhage who had return of vision after prolonged periods of blindness. The purpose of this report is to review these 2 cases and to discuss the likely pathophysiology and appropriate therapy.

\section{Case reports}

CASE 1

While working with a screwdriver a 37-year-old male accidentally slipped, causing a puncture injury to his

Correspondence to B. Katz, MD, Department of Ophthalmology, University of Arizona Health Sciences Center, Tucson, AZ 85724, USA. left orbit superonasally. Immediately after the accident the vision was normal and there was minimal external bleeding. Within 30 minutes he was aware of loss of vision, with periorbital pain and swelling. An examination was performed by an ophthalmologist approximately one hour after the accident. Visual acuity was 20/20 OD, no light perception OS. The left orbit was tense, the left pupil in mid position and unreactive, and ductions of the left eye were restricted to all fields of gaze. Anterior chamber paracentesis was performed without return of vision.

The patient was seen at the University of Arizona for further evaluation 4 hours after the accident and some $3 \frac{1}{2}$ hours after the onset of his total blindness OS. Visual acuity was 20/20 OD, no light perception OS. A $6 \mathrm{~mm}$ laceration was noted above the left upper eyelid. The left globe was proptotic and there were extensive periorbital ecchymoses. The left pupil had no direct but normal consensual response. The left cornea was clear, but the anterior chamber was shallowed. Examination of the fundus showed what appeared to be normal retinal vasculature and choroidal blood flow bilaterally, with no signs suggestive of oedema or intraretinal haemorrhage.

The patient was treated with $100 \mathrm{~g}$ of mannitol intravenously, and a lateral canthotomy was performed. During the canthotomy the patient reported return of vision, and acuity was recorded as hand movements. The wound was then explored and the orbit decompressed through a transconjunctival approach. No obvious clots or localised areas of haemorrhage were identified. The anterior chamber spontaneously reformed during the procedure, and indirect ophthalmoscopy again revealed a normal 


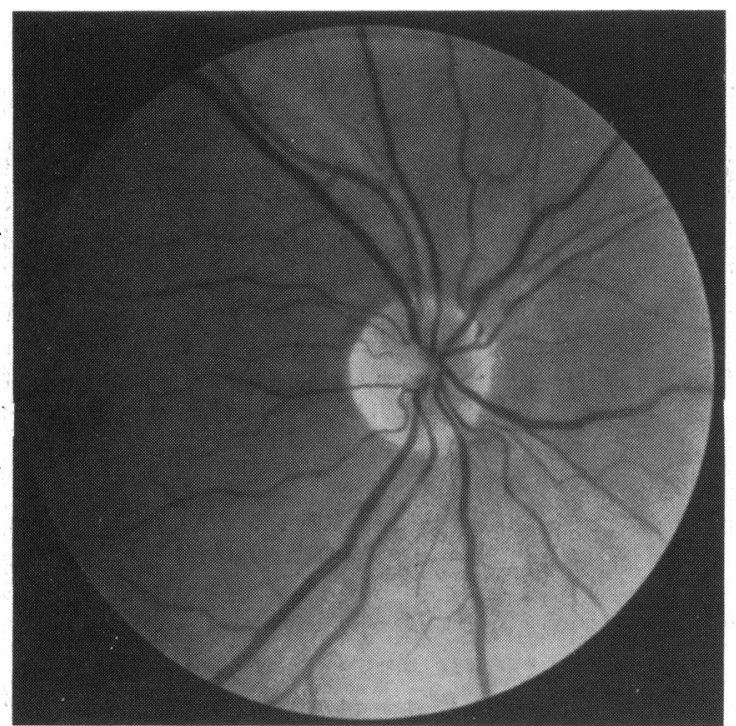

Fig. 1 Case 1. Left eye. Optic disc and peripapillary retina 17 days after trauma.

posterior pole with apparently normal vasculature and blood flow.

On the first postoperative day visual acuity had improved to counting fingers at 3 feet $(90 \mathrm{~cm})$. Proptosis had decreased, the left pupil showed a mild afferent defect, and ocular motility had returned to normal. The cornea was clear and the anterior chamber deep. The left fundus showed normal retinal

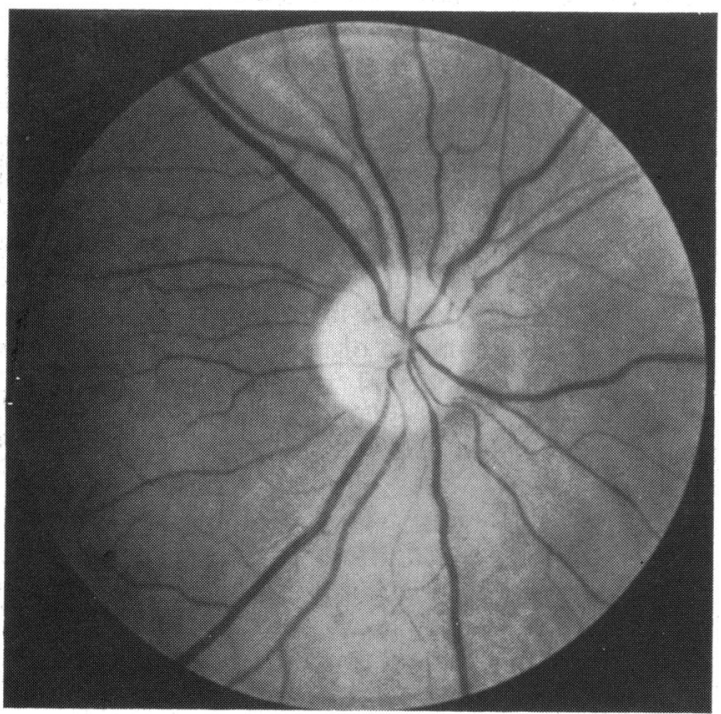

Fig. 2 Case 1. Left eye. Optic disc and peripapillary retina 6 weeks after trauma, illustrating optic atrophy and loss of nerve fibre layer. and choroidal vasculature, without evidence of retinal oedema. Visual field testing on a Goldmann perimeter revealed a large centrocoecal scotoma breaking out to the periphery, associated with an altitudinal defect seen only with small isoptres.

Seventeen days after his initial accident visual acuity had returned to $20 / 60$, while his afferent pupillary defect remained. Fundus examination showed the disc with minimal temporal pallor (Fig. 1). Visual field testing showed a paracentral scotoma and persisting altitudinal defect. Six weeks after the accident his visual acuity had returned to $20 / 40$, though his pupillary reaction and visual field remained unchanged. The fundus showed diffuse loss of nerve fibres, with temporal pallor of the disc (Fig. 2).

\section{CASE 2}

A 65-year-old woman fell to the ground, injuring her left periorbital region. The skin was not broken and vision was normal. Within 5 minutes of the injury she noted pain and swelling about the left orbit and total visual loss in her left eye.

On presenting to the Ophthalmology Clinic 3 hours after injury her visual acuity was measured at no light perception OS. The globe was proptotic, there were periorbital oedema and ecchymoses, and the pupil was fixed and in mid position. The cornea was clear and the anterior chamber was formed. Intraocular pressure by applanation was $57 \mathrm{mmHg}$. Faint pulsations were observed in the central retinal artery. Immediate surgical decompression of the orbit by lateral canthotomy and cantholysis was performed. Within 30 minutes of this treatment, which occurred some $4 \frac{1}{2}$ hours after her injury, the patient's vision returned to light perception and her intraocular pressure fell to $31 \mathrm{mmHg}$. Over the next hour the visual

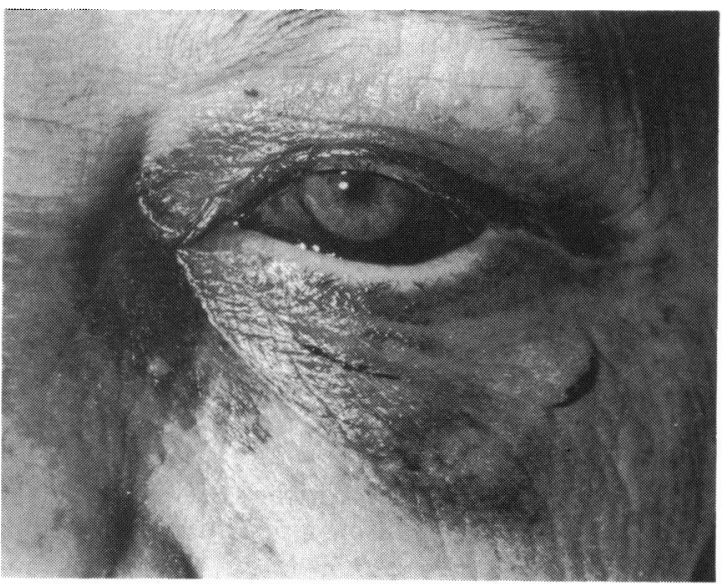

Fig. 3 Case 2. External anatomy, one day following orbital decompression. 


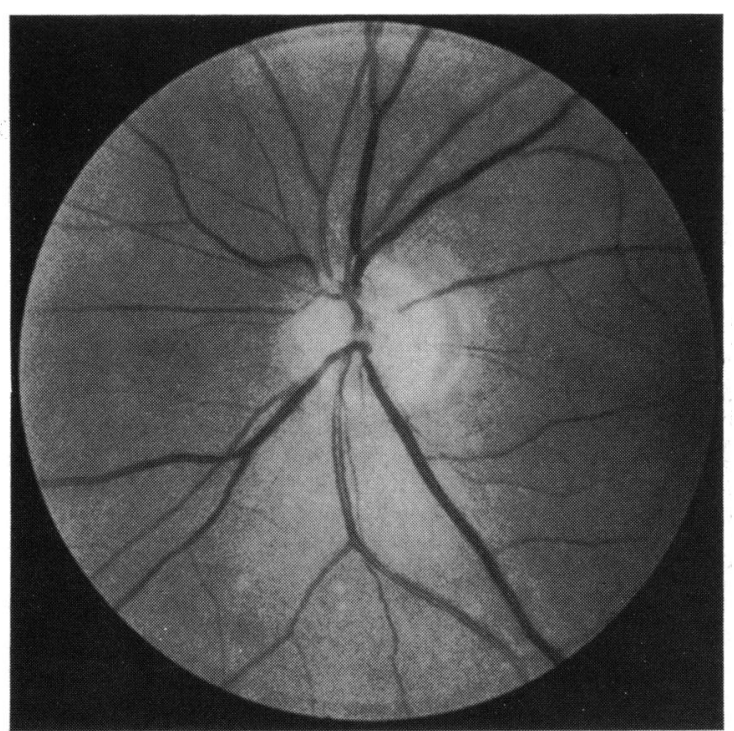

Fig. 4 Case 2. Left eye. Optic disc and peripapillary retina one day after trauma.

acuity improved to $20 / 80$, and intraocular tension decreased to $21 \mathrm{mmHg}$.

By the next day her visual acuity had improved to 20/30 OS, and proptosis had decreased (Fig. 3). An afferent pupillary defect was noted. Ocular motility was full, though the patient complained of pain on upgaze. The posterior pole was normal to direct and indirect ophthalmoscopy (Fig. 4). Visual field testing to confrontation was normal. Fluorescein angiography showed normal retinal and choroidal circulations, without signs of retinal or disc oedema (Fig. 5). $X$-rays showed the presence of an orbital floor fracture on that side.

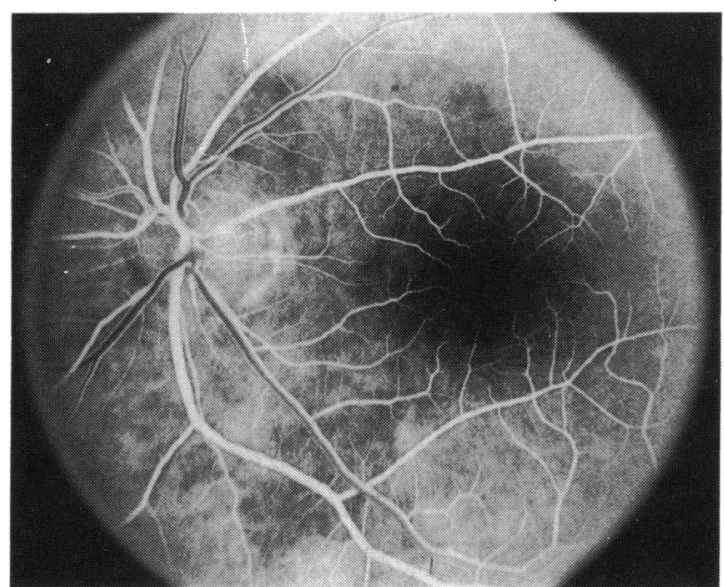

Fig. 5 Case 2. Left eye. Fluorescein angiography one day after trauma, illustrating normal pattern of retinal and choroidal circulation during early $A-V$ phase.

\section{Discussion}

Visual loss from orbital haemorrhage is related to the surgical anatomy of the orbital cavity. The orbit is a poorly expandable space comparable to the cranial cavity. It is bounded posteriorly and on its sides by rigid bony structures. Anteriorly it is limited by the globe and the orbital septum. Any demand for expansion of this orbital space can be met only by the anterior displacement of the globe and septum. There is some limited capacity for forward displacement by stretching of the septum, but once this limit of proptosis has been reached the globe acts as a plug in a fully distended palpebral fissure. The orbit is then 'sealed' by its anterior 'wall'. That the orbit is sealed posteriorly as well is shown by the fact that orbital haemorrhages do not spontaneously decompress themselves by dissecting intracranially.

When orbital haemorrhage occurs, the globe moves forward until it reaches the orbit's anatomical boundary. As further bleeding occurs into the orbital space, which is now a closed cavity, there can be little increase in volume to accommodate any increase in pressure, which is distributed equally throughout the entire orbital contents. It is this increased orbital pressure acting on the vascular supply of the globe and optic nerve which probably accounts for reversible visual loss from orbital haemorrhage.

Three possible separate circulations may be affected: the retinal circulation, the choroidal circulation, or the blood supply to the optic nerve itself. The normal appearance of blood flow in our patients' retinal and choroidal circulations as observed by ophthalmoscopy and shown by fluorescein angiography speaks for the integrity of the retinal and choroidal vasculature. The presence of an intact consensual response of the ipsilateral pupil (case 1) demonstrates some integrity of the iris sphincter, and therefore the anterior ciliary circulation. The lack of return of vision after anterior chamber paracentesis (case 1) makes it unlikely that high intraocular pressure (with choroidal or retinal ischemia) is causative.

The visual loss we observed was not associated with signs of retinal, choroidal, or disc oedema. It was characterised by return of central acuity, though accompanied by an afferent pupillary defect, diffuse loss of nerve fibres, descending optic atrophy, and an altitudinal field defect (case 1). These signs carry the signature of optic nerve dysfunction, and are best explained by a posterior injury to the optic nerve. A recent report of a case of visual loss from orbital haemorrhage in which the visual evoked response (VER) was unrecordable at a time when the ERG was normal ${ }^{12}$ lends electrophysiological evidence to this entity's being an optic neuropathy. 
Whether the optic nerve dysfunction is due to ischaemia as a primary event or secondary to compression cannot be ascertained. Precisely where in its intraorbital or intracanalicular course the optic nerve is compromised remains conjectural, as do the effects of ischaemia and compression on optic nerve axonal transport. The clinical courses of both our patients, however, discount the pathophysiological mechanisms of central retinal artery occlusion, central retinal vein occlusion, anterior ischaemic optic neuropathy, or acutely raised intraocular pressure as being the cause of visual loss seen with retrobulbar haemorrhage.

Whatever the actual pathophysiology may be, the appropriate therapeutic manoeuver is immediate orbital decompression. Attempts to lower intraocular pressure are not appropriate, since intraocular circulations are not the limiting physiological factors. Medical therapy with the use of osmotic diuretics to decrease oedema helps to decompress the orbit, but prompt surgical intervention in the form of immediate canthotomy and/or cantholysis, in the clinic or in the emergency room, is the treatment of choice.

We believe these cases represent the longest documented interval (4 hours) of reversible total blindness due to orbital haematoma. They suggest that the optic nerve is more resilient when rendered ischaemic than the retina or choroid, and offer observations to support recent demonstrations that axons can resist ischaemia longer than nerve cell bodies. ${ }^{32}$ Both patients had no perception of light for at least $3 \frac{1}{2}$ hours, yet they recovered to $20 / 40$ and $20 / 20$ acuity respectively. Experimental studies suggest that the retina tolerates temporary ischaemia up to 100 minutes before potential for recovery of vision is lost. ${ }^{33-35}$ The optic nerve tolerance time to acute ischaemia has not been established experimentally, but if ischaemia were the injury in our cases, these patients' courses suggest it may be 240 minutes or longer.

Our cases illustrate that the optic nerve, and possibly its vascular supply, may become compromised and account for visual loss seen in the setting of orbital haemorrhage, and that decompression of a tense, tight orbit, when done in time, can successfully reverse a mechanical posterior optic neuropathy even in the setting of prolonged blindness.

The authors are grateful to Dr Stewart White for allowing us to see case 1 .

\section{References}

1 Anderson RL. Bilateral visual loss after blepharoplasty. Arch Ophthalmol 1981;99: 2205.

2 Anderson RL, Edwards JJ. Bilateral loss after blepharoplasty. Ann Plast Surg 1980; 5: 288-92.
3 Putterman AM. Temporary blindness after cosmetic blepharoplasty. Am J Ophthalmol 1975; 80: 1081-3.

4 Hartley JH, Lester JR, Schatter WE. Acute retrobulbar hemorrhage during elective blepharoplasty. Plast Reconstr Surg 1973; 52: 8-15.

5 Heinze JB, Hueston JT. Blindness after blepharoplasty: mechanism and early reversal. Plast Reconstr Surg 1978; 61: 347-54.

6 Hueston JT, Heinze JB. Successful early relief of blindness occurring after blepharoplasty. Plast Reconstr Surg 1974; 53: 588-92.

7 Hueston JT, Heinze JB. Successful early relief of blindness occurring after blepharoplasty. Plast Reconstr Surg 1977; 59: 430-1.

8 Fry $\mathrm{HJH}$. Reversible visual loss after proptosis from retrobulbar hemorrhage. Plast Reconstr Surg 1969; 44: 480-3.

9 Jarrett WH, Brockhurst RJ. Unexplained blindness and optic atrophy following retinal detachment surgery. Arch Ophthalmol 1965; 73: 782-91.

10 Long JC, Ellis PP. Total unilateral visual loss following orbital surgery. Am J Ophthalmol 1971; 71: 218-20.

11 Nicholson DH, Guzak SV. Visual loss complicating repair of orbital floor fractures. Arch Ophthalmol 1971; 86: 369-75.

12 Emery JM, Huff JD, Justice J. Central retinal artery occlusion after blow-out fracture repair. Am J Ophthalmol 1974; 78: 538-40.

13 Johnson LP, Parkin JL. Blindness and total ophthalmoplegia: a complication of transantral ligation of the internal maxillary artery for epistaxis. Arch Otolaryngol 1976; 102: 501-4.

14 Thompson JN, Niccole MW, Wong E, Passy V, Konut RI. Blindness following frontal sinus irrigation. Arch Otolaryngol 1980; 106: 358-60.

15 Butt WD. Sudden blindness following reduction of a malar fracture. Ann Plast Surg 1979; 2: 522-4.

16 Varley WEB. Holt-Wilson AD, Watson PG. Acute retinal arterial occlusion following reduction of a fractured zygoma and its successful treatment. Br J Oral Surg 1968; 6: 31-6.

17 Muller PJ, Deck JHN. Intraocular and optic nerve sheath hemorrhage in cases of sudden intracranial hypertension. $J$ Neurosurg 1974; 41: 160-5.

18 Krohel GB, Wright JE. Orbital hemorrhage. Am J Ophthalmol 1979; 88: 254-8.

19 Chandler JR, Langenbrunner DJ, Stevens ER. The pathogenesis of orbital complications in acute sinusitis. Laryngoscope 1970; 80: 1414-28.

20 Rounthwaite FJ. Sinusitis and the blind eye. Can J Otolaryngol 1978; 3: 219-24.

21 Schramm VL, Meyers EN, Kennerdell JS. Orbital complications of acute sinusitis: evaluation, management and outcome. Otolaryngology 1978; 86: 221-30.

22 Welsh LW, Welsh JJ. Orbital complications of sinus disease. Laryngoscope 1974; 84: 848-56.

23 Stewart DJ, Polomeno C. Total visual loss and orbital foreign bodies. Can J Ophthalmol 1979; 14: 95-8.

24 Gold RS, Sagar E. Pansinusitis, orbital cellulitis, and blindness as a sequelae of delayed treatment of dental abscess. J Oral Surg 1974; 32: 40-3.

25 Jones IS. Lymphangiomas of the ocular adnexa. Trans Am Ophthalmol Soc 1959; 57: 602-65.

26 Reese AB, Howard GM. Unusual manifestations of ocular lymphangioma and lymphangiectasis. Surv Ophthalmol 1973; 18: 226-31.

27 Petrelli RL, Petrelli EA, Allen WE. Orbital hemorrhage with loss of vision. Am J Ophthalmol 1980; 89: 593-7.

28 Rubinstein RA, Albert DM, Scheie HG. Ocular complications of hemophilia. Arch Ophthalmol 1966; 76: 230-2.

29 Zimmerman A, Merigan TC. Retrobulbar hemorrhage in a hemophiliac with irreversible loss of vision. Arch Ophthalmol 1960 64: 949-50. 
30 Kubik J. Spontaneous hemorrhage into the orbit in hypertension. Cesk Oftalmol 1963; 19: 267-9.

31 Dunnington JH. Exophthalamos in infantile scurvy. Arch Ophthalmol 1931; 6: 731-9.

32 Radius RL, Anderson DR. Reversibility of optic nerve damage in primate eyes subjected to intraocular pressure above systolic blood pressure. Br J Ophthalmol 1981; 65: 661-72.
33 Kroll AJ. Experimental central retinal artery occlusion. Arch Ophthalmol 1968; 79: 453-8.

34 Hamasaki DT, Kroll AJ. Experimental central retinal artery occlusion. Arch Ophthalmol 1968; 80: 243-8.

35 Smith GG, Baird CD. Survival time of retinal cells deprived of the blood supply by increased intraocular pressure. Am J Ophthalmol 1952; 35: 133-6. 